\title{
Erratum to: On the Correlation Properties of Thermal Noise in Fluids
}

\author{
Vladimír Lisý • Jana Tóthová • Lukáš Glod
}

Published online: 30 October 2014

(C) Springer Science+Business Media New York 2014

\section{Erratum to: Int J Thermophys (2013) 34:629-641 DOI 10.1007/s10765-012-1290-1}

Equation 11 in the original article [1] should read

$$
\phi(t)=\frac{k_{\mathrm{B}} T}{M} \frac{1}{\lambda_{1}-\lambda_{2}}\left[\lambda_{1} \exp \left(\lambda_{1}^{2} t\right) \operatorname{erfc}\left(-\lambda_{1} \sqrt{t}\right)-\lambda_{2} \exp \left(\lambda_{2}^{2} t\right) \operatorname{erfc}\left(-\lambda_{2} \sqrt{t}\right)\right] .
$$

In the published paper the two terms in the square brackets are $\lambda_{1} \exp \left(\lambda_{2}^{2} t\right) \operatorname{erfc}$ $\left(-\lambda_{2} \sqrt{t}\right)-\lambda_{2} \exp \left(\lambda_{1}^{2} t\right) \operatorname{erfc}\left(-\lambda_{1} \sqrt{t}\right)$. As pointed out by J. M. Ortiz de Zárate (personal communication), in this case Eq. 11 (which correctly describes the hydrodynamic Brownian motion) is exactly the same as Eq. 6 (possessing an incorrect solution for the velocity autocorrelation function (VAF)). This is seen if the coefficients $C_{i}$ in Eq. 6 are expressed in the form $C_{1}=-\lambda_{2} /\left(\lambda_{1}-\lambda_{2}\right)$ and $C_{2}=\lambda_{1} /\left(\lambda_{1}-\lambda_{2}\right)$ (Ortiz de Zárate, personal communication).

The formulas following Eq. 11 use the above given equation and are correct. They agree with the previously obtained expressions for the VAF (see [2] and references therein).

The online version of the original article can be found under doi:10.1007/s10765-012-1290-1.

\section{Lisý $(\varangle) \cdot$ J. Tóthová}

Department of Physics, Technical University of Košice, Park Komenského 2, 04200 Košice, Slovakia e-mail: vladimir.lisy@tuke.sk

\section{Glod}

Department of Mathematics and Physics, University of Security Management, Kukučínova 17, 04001 Košice, Slovakia 
Acknowledgment We are grateful to Prof. José María Ortiz de Zárate who turned our attention to the misprints in Eq. 11.

\section{References}

1. V. Lisý, J. Tóthová, L. Glod, Int. J. Thermophys. 34, 629 (2013)

2. J. Tóthová, G. Vasziová, L. Glod, V. Lisý, Eur. J. Phys. 32, 645 (2011) 